\title{
Analisis Morfotektonik pada Aliran Sungai di Kabupaten Kutai Timur, Kalimantan Timur
}

\author{
Muh. Farid Wajedy, Muhammad Fawzy Ismullah Massinai*, Muhammad Altin Massinai, \\ Hasanuddin \\ Departemen Geofisika. Fakultas Matematika dan Ilmu Pengetahuan Alam. Universitas Hasanuddin, \\ Makassar, Indonesia
}

\begin{abstract}
* Corresponding author: fawzy@sci.unhas.ac.id Received: Jan 7, 2021; Accepted: Jun 16, 2021. DOI: $10.31764 /$ jpl.v2i1.3827
\end{abstract}

\begin{abstract}
Abstrak. Kabupaten Kutai Timur merupakan salah satu kabupaten yang terletak di Provinsi Kalimantan Timur. Kabupaten ini memiliki tujuh buah sungai yang memiliki Daerah Aliran Sungai (DAS) masing - masing. Pengelolaan DAS dapat dilakukan melalui analisa geomorfologi dengan melakukan pendekatan bentang lahan untuk mengetahui tektonik yang bekerja pada daerah tersebut. Analisa morfotektonik yang dilakukan pada penelitian ini adalah analisa pola pengairan dan sinusitas sungai. Tujuan dari penelitian ini adalah untuk mengetahui keaktifan proses tektonik yang terjadi di Kabupaten Kutai Timur. Data yang digunakan adalah data aliran sungai. Data ini diolah untuk mengetahui aliran sungai yang berada di wilayah tersebut. Setelah itu panjang sungai dan kelurusan sungai diukur lalu sinusitas dari sungai tersebut dihitung. Pola pengaliran dendritic dan trellis dijumpai pada daerah ini. Daerah tenggara dan timur laut memiliki kemiringan lereng yang landai yang ditunjukkan oleh sungai berpola dendritic. Di arah barat laut terdapat sejumlah lipatan yang ditandai oleh sungai berpola trellis. Nilai sinusitas sungai yang didapatkan semua aliran sungai memiliki nilai di atas 1,5 yang artinya daerah ini memiliki aktivitas tektonik yang aktif. Hal ini juga didukung oleh keberadaan sesar aktif yaitu Sesar Mangkalihat. Hasil dari penelitian ini dapat digunakan sebagai informasi baru dalam pengelolaan DAS di Kabupaten Kutai Timur, Provinsi Kalimantan Timur.
\end{abstract}

Kata Kunci: DAS, pola pengaliran, morfotektonik, sinusitas sungai

\begin{abstract}
East Kutai Regency is one of the regencies located in East Kalimantan Province. This regency has seven rivers that have their respective watersheds. Watershed management can be done through geomorphological analysis by using a landscape approach to determine the tectonics that work in the area. Morphotectonic analysis in this study is an analysis of drainage patterns and river sinuosity. The aim of this study was to determine the activity level of tectonic processes that occur in East Kutai Regency. The data used is river stream data. This data is processed to determine the flow of rivers in the area. After that, the length and the lineament of the river are measured and river sinuosity is calculated. Dendritic and trellis drainage patterns were found in this area. The southeast and northeast areas have a gentle slope indicated by a dendritic pattern. There are a number of folds marked by a trellis pattern the northwest. The river sinuosity index of all rivers has a value above 1.5 , which means this area has active tectonic activity. This is also supported by the presence of an active fault, the Mangkalihat Fault. The results of this study can be used as new insight in watershed management in East Kutai Regency, East Kalimantan Province.
\end{abstract}

Keywords: watershed, drainage pattern, morphotectonics, river sinuosity

\section{Pendahuluan}

Kabupaten Kutai Timur merupakan salah satu kabupaten yang terletak di Provinsi Kalimantan Timur. Kabupaten ini memiliki tujuh buah sungai yang memiliki Daerah Aliran Sungai (DAS) masing - masing. DAS adalah daerah yang dibatasi oleh punggung bukit dan berfungsi sebagai penyimpan dan penyalur air, sedimen unsur-unsur hara dalam sistem sungai yang semuanya keluar melalui satu titik tunggal (Vienastra, 2018).

Suatu DAS mempunyai peranan penting dalam penyelidikan morfologi suatu daerah. Pengelolaan DAS dapat dilakukan melalui analisa geomorfologi dengan melakukan pendekatan bentang lahan sebagai acuan dasar dalam mengetahui tektonik yang bekerja pada daerah tersebut (Vienastra, 2018). 
Penelitian geomorfologi tektonik pada dasarnya adalah meneliti bentangalam suatu daerah dikaitkan dengan tektonik yang menyebabkan terjadinya bentangalam tersebut. Proses tektonik adalah proses saat suatu gaya yang bekerja pada bagian suatu lempeng yang mengakibatkan bagian lempeng tersebut bergerak baik secara vertikal maupun horizontal. Pendekatan yang dilakukan pada penelitian geomorfologi tektonik pada suatu daerah dapat dilakukan dengan analisis parameter morfotektonik.

Morfotektonik merupakan suatu karakter bentangalam yang berhubungan dengan proses tektonik, karakteristik bentangalam secara kuantitatif dapat memberikan pengetahuan tentang morfotektonik. Pada skala lokal dan regional tektonik dapat dilihat dari kenampakan bentangalam yang khas seperti gawir, bentuk lembah, kelurusan perbukitan, keselurusan sungai, pola pengaliran dan lain - lain (Sukiyah et al., 2012). Analisis morfotektonik dibutuhkan untuk menganalisis hubungan karakteristik bentang alam dan tingkat aktivitas tektonik (Wahyudi et al., 2015). Analisis ini antara lain sinusitas sungai (Timár, 2003; Massinai, 2015; Xiao et al., 2020), kelurusan sungai (Wahyudi et al., 2015; Zulkifli et al., 2019; Hayani and Sutriyono, 2020), basin asimetri (Massinai, 2015; Hayani and Sutriyono, 2020), indeks gradien panjang sungai (Massinai, 2015; Wahyudi et al., 2015; Hayani and Sutriyono, 2020), rasio tinggi dan lebar lembah (Massinai, 2015; Wahyudi et al., 2015; Hayani and Sutriyono, 2020), sinusitas pegunungan muka (Massinai, 2015; Wahyudi et al., 2015; Zulkifli et al., 2019; Hayani and Sutriyono, 2020) segmen sungai (Massinai, 2015), kurva hipsometrik (Massinai, 2015) dan kestabilan lereng (Massinai, 2015). Di antara analisis tersebut, sinusitas sungai adalah salah satu yang sering digunakan luas (Xiao et al., 2020).

Analisa morfotektonik yang dilakukan pada penelitian ini adalah analisa pola pengairan dan sinusitas sungai. Tujuan dari penelitian ini adalah untuk mengetahui keaktifan proses tektonik yang terjadi di Kabupaten Kutai Timur. Hasil dari penelitian ini diharapkan mampu menjadi tambahan wawasan dalam pengelolaan DAS di Kabupaten Kutai Timur, Provinsi Kalimantan Timur.

Secara geologi regional, Pulau Kalimantan tersusun atas berbagai batuan dasar yang merupakan tipe asal benua, Samudra, dan transisi. Cekungan Barito yang berada di bagian selatan Kalimantan terletak di atas batuan dasar Schwaner asal benua di bagian barat dan di bagian timurnya dilandasi oleh accereted crust dari Pegunungan Meratus. Ke arah utara, Cekungan Kutai dibatasi oleh accereted crust dari Tinggian Kuching (bagian dari Central Range) dan batuan dasar asal benua Mangkalihat di bagian barat dan utaranya. Cekungan Tarakan, yang yang berada lebih utara dari Kutai, dibatasi oleh accereted crust Dent-Semporna, Tinggian Sekatak - Berau, basement asal benua Mangkalihat. Hubungan terrane-terrane basement ini tidak sepenuhnya dipahami. Beberapa batas ini mungkin merupakan suture yang mengindikasikan jejak zona collision atau zona sesar utama (Pusat Studi Gempa Nasional, 2017).

Tiga sesar utama yang telah diidentifikasi di pulau Kalimantan yaitu Sesar Tarakan, Mangkalihat, dan Meratus. Sesar - sesar tersebut memiliki panjang lebih dari $100 \mathrm{~km}$ yang dapat berpotensi menimbulkan gempa dengan magnitudo 7. Sesar mendatar Tarakan dapat dikenali di bagian utara pulau ini yang terbentang mulai dari daratan sampai menerus ke lepas pantai. Zona sesar anjak dikenali di bagian selatan Pulau Kalimantan, yaitu Sesar Meratus dengan arah NE-SW. Sesar Mangkalihat yang berupa sesar mendatar, diidentifikasi di pantai timur Pulau Kalimantan (Pusat Studi Gempa Nasional, 2017). Sesar ini diduga mempengaruhi kondisi morfologi Kabupaten Kutai Timur.

\section{Metode Penelitian}

Pola pengaliran (drainage pattern) adalah hubungan antara satu sungai dengan lainnya atau hubungan antara air permukaan yang mengalir melalui lembah - lembah. Sungai di dalam semua DAS mengikuti suatu aturan yaitu bahwa aliran sungai dihubungkan oleh suatu jaringan satu arah yaitu cabang dan anak sungai mengalir ke dalam sungai induk yang lebih besar dan membentuk suatu pola tertentu. Pola tersebut bergantung pada kondisi topografi, geologi, iklim, vegetasi yang terdapat di dalam DAS yang bersangkutan. Secara keseluruhan kondisi tersebut akan menentukan karakteristik sungai di dalam bentuk polanya (Massinai, 2015). 


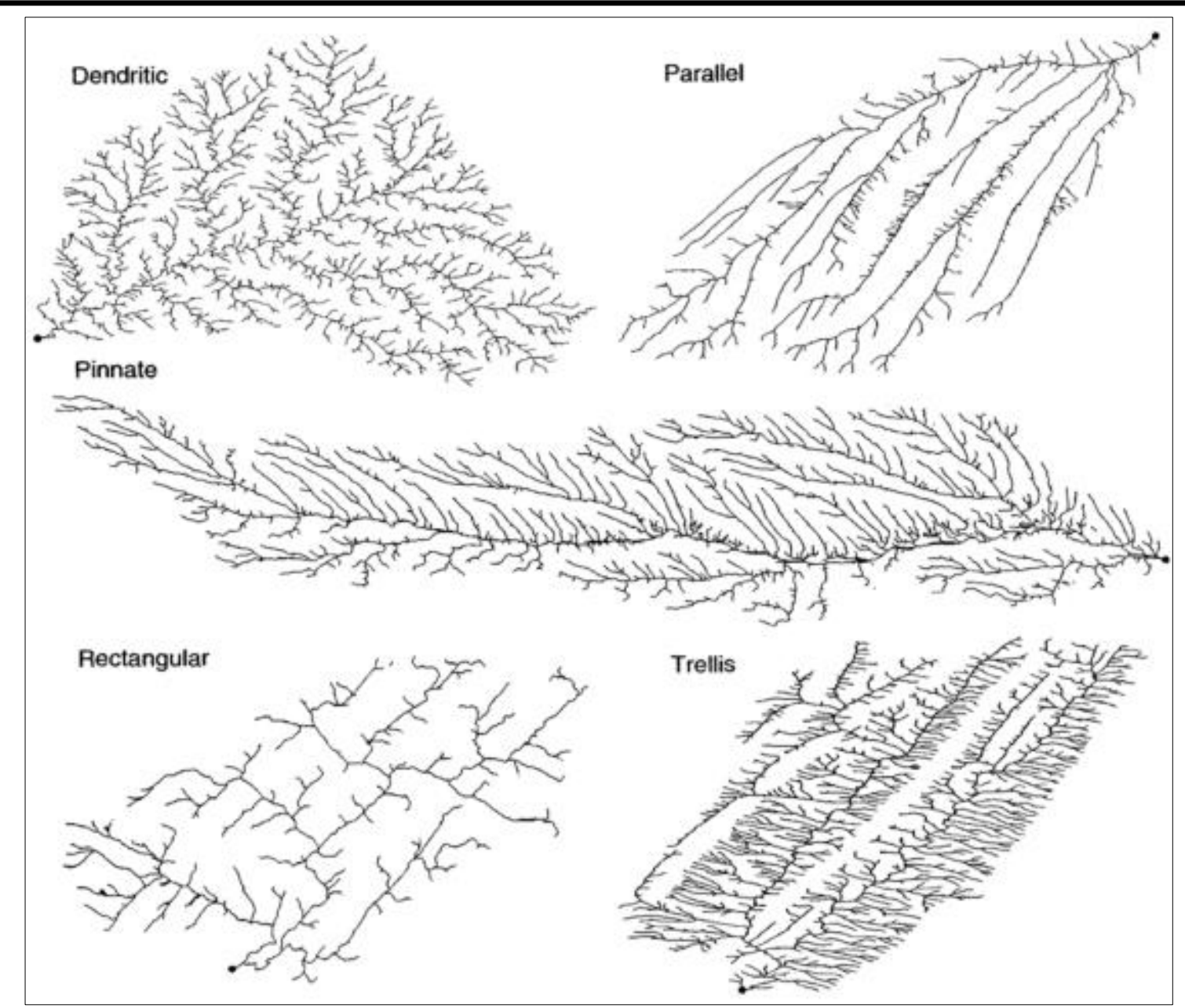

Gambar 2. Beberapa pola pengaliran (drainage pattern) (Mej1a and Niemann, 2008).

Pola pengaliran dari suatu DAS dapat merupakan petunjuk awal tentang jenis dan struktur batuan yang ada. Petunjuk ini diperlukan untuk berbagai rencana konstruksi bangunan sipil. Gambar 1 memperlihatkan berbagai pola pengaliran. Pola pengaliran dendritik (dendritic) berbentuk menyerupai percabangan pohon yang menyebar dengan beragam ukuran, aluran irregular, menyusuri jalur ke banyak arah dan anak sungainya cenderung bergabung pada sudut yang tajam. Pola pengaliran parallel atau sejajar memiliki aliran utama yang lurus dan sejajar serta anak sungainya bergabung pada sudut yang sangat tajam. Pola pengaliran pinnate terlihat seperti bulu unggas dengan jalur utama sangat lurus dan berorientasi pada satu arah saja serta kebanyakan anak sungainya bergabung dengan aliran utama dengan interval teratur dan sudut yang tajam. Pola pengaliran rectangular memiliki sinusitas jalur sungai dengan sudut yang besar yang cenderung $90^{\circ}$ dan anak sungainya tergabung di sudut yang terdekat. Pola pengaliran trellis menyerupai kisi kisi yang teratur secara geometris sebab anak sungainya banyak dan pendek jika dibandingkan dengan alur sungai utama (Mej1a and Niemann, 2008).

Pola pengaliran memiliki hubungan dengan bedrock, tanah, tektonik, iklim dan proses erosi. Dendritik cenderung terjadi di daerah dengan kemiringan lereng yang landai dan litologi yang relatif seragam. Parallel biasanya terjadi pada daerah dengan kemiringan lereng yang moderat hingga curam. Pinnate dapat terjadi pada daerah dengan kemiringan lereng yang sangat curam. Rectangular terjadi pada daerah yang memiliki kekar dan/ atau sesar yang bertemu pada sudut yang tepat. Kekar dan/ atau sesar tersebut berada pada zona lemah yang digunakan oleh air untuk mengembangkan aliran sungai. Trellis biasanya terjadi pada daerah lipatan atau lapisan yang terlipat yang membentuk satuan sesar yang sejajar. (Mejıa and Niemann, 2008). 
Sinusitas sungai adalah suatu paremeter yang digunakan dalam menganalisa proses tektonik yang terjadi pada suatu daerah. Sinusitas dari aliran sungai dapat dicari dengan menggunakan persamaan berikut (Massinai, 2015):

$$
\text { Sinusitas }=\frac{\text { Panjang alur sungai }}{\text { panjang garis lurus sungai }}
$$

Hasil perhitungan nilai sinusitas sungai, proses tektonik suatu daerah dapat diklasifikasikan sebagai berikut:

Tabel 1. Klasifikasi tektonik berdasarkan nilai sinusitas sungai (Massinai, 2015).

\begin{tabular}{cccc}
\hline No & Sinusitas & Jenis & Tektonik \\
\hline 1 & $<1.0$ & Lurus & Rendah \\
2 & $1.05-1.5$ & Sinus & Sedang \\
3 & $>1.5$ & Berliku & Aktif \\
\hline
\end{tabular}

Tabel 1 memperlihatkan hubungan indeks sinusitas sungai dengan implikasi proses tekoniknya. Semakin tinggi indeks sinusitasnya menunjukkan semakin tinggi proses tektoniknya. Sungai berliku biasanya dipengaruhi oleh proses geomorfologi seperti gerakan tanah (Massinai, 2015) dan aktivitas erosional (Augustio and Setiawan, 2019).

Metode yang digunakan pada penelitian ini adalah analisa pola pengaliran serta analisa parameter mofometri sinusitas sungai pada Daerah Aliran Sungai (DAS) di Kabupaten Kutai Timur, Provinsi Kalimantan Timur. Data yang digunakan pada penelitian ini adalah data sekunder bersumber dari Badan Informasi Geospasial (BIG) yang dapat diakses melalui situs tanahair.indonesia.go.id. Data tersebut berupa data aliran sungai serta data batas wilayah yang berlokasi di Kabupaten Kutai Timur Provinsi Kalimantan Timur (Gambar 2). Selanjutnya data diolah untuk memetakan batas wilayah Kabupaten Kutai Timur dan mengetahui aliran-aliran sungai yang berada di wilayah tersebut. Setelah itu panjang sungai dan kelurusan sungai yang terdapat di Kabupaten Kutai Timur diukur kemudian untuk sinusitas dari sungai tersebut dihitung menggunakan aplikasi tabulasi. Interpretasi dilakukan dengan menghubungkan hasil dengan Tabel 1 dan beberapa referensi lainnya yang relevan.

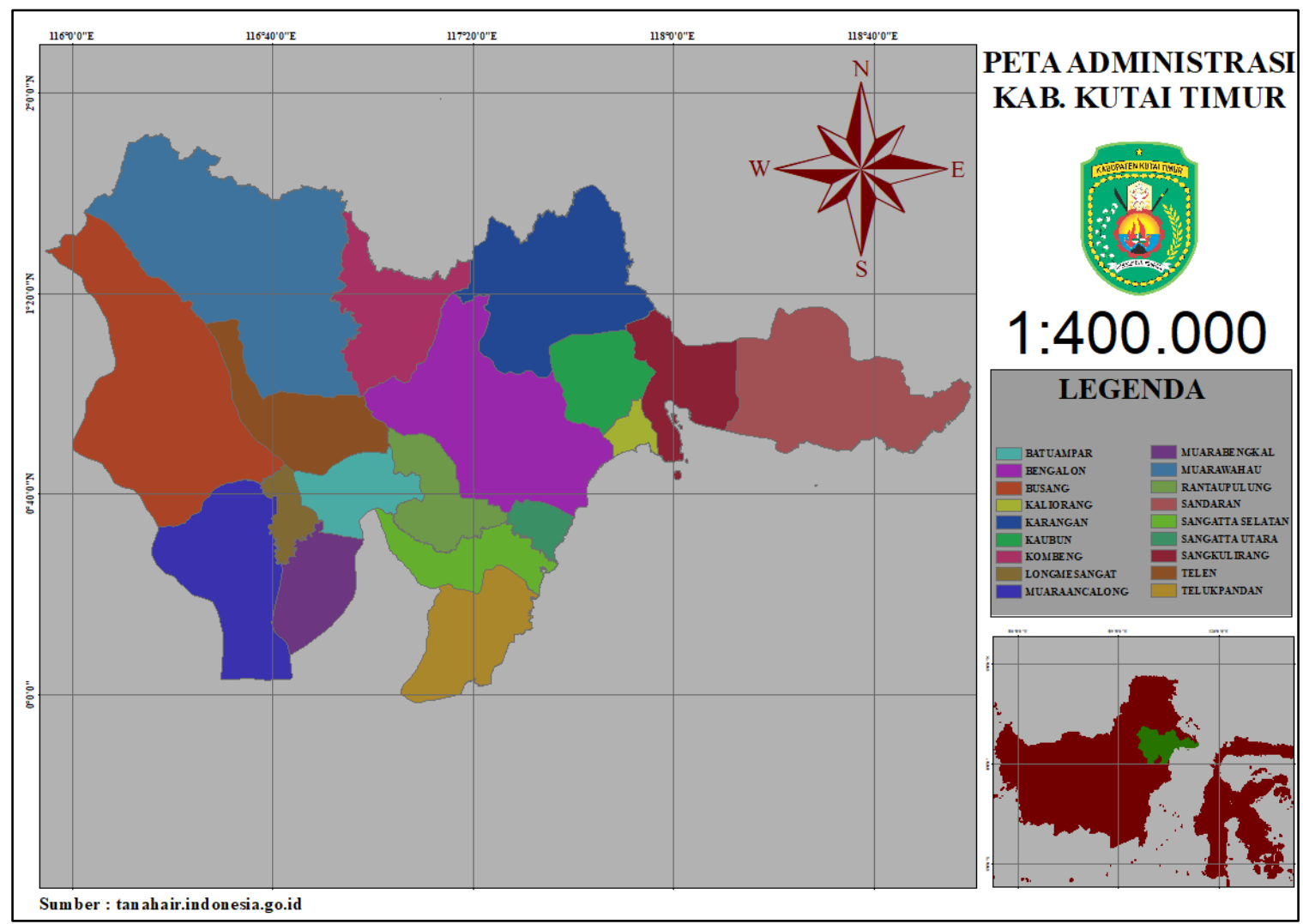

Gambar 2. Peta Lokasi Penelitian 


\section{Hasil dan Pembahasan}

Pola pengaliran yang terlihat secara umum di Kabupaten Kutai Timur didominasi oleh pola pengaliran dendritic dan trellis. Hasilnya dapat dilihat pada Gambar 3. Pola pengaliran trellis cenderung berada di area berarah Barat Laut yang terhubung dengan sungai berpola dendritic di Tenggara, sedangkan di area Timur Laut terdapat pula sungai berpola dendritic.

Daerah Tenggara dan Timur Laut memiliki kemiringan lereng yang landai yang ditunjukkan oleh sungai berpola dendritic. Pola pengaliran ini menunjukkan kondisi fisik daerahnya berupa material kedap air dan teksturnya relatif halus. Genesa perkembangan pola pengaliran ini berada pada (Massinai, 2015):

- Daerah dengan variasi sudut lereng kecil, landai, dan berelief rendah;

- Daerah dengan struktur lapisan horizontal, miring landai, atau terlipat lemah;

- Daerah berbatu metamorf, sedimen, beku asalkan daya tahan terhadap erosi seragam.

Di arah Barat Laut terdapat sejumlah lipatan yang ditandai oleh sungai berpola trellis. Pola ini dapat menjadi ciri daerah terlipat, antiklin, sinklin, dan kubah (Massinai, 2015).

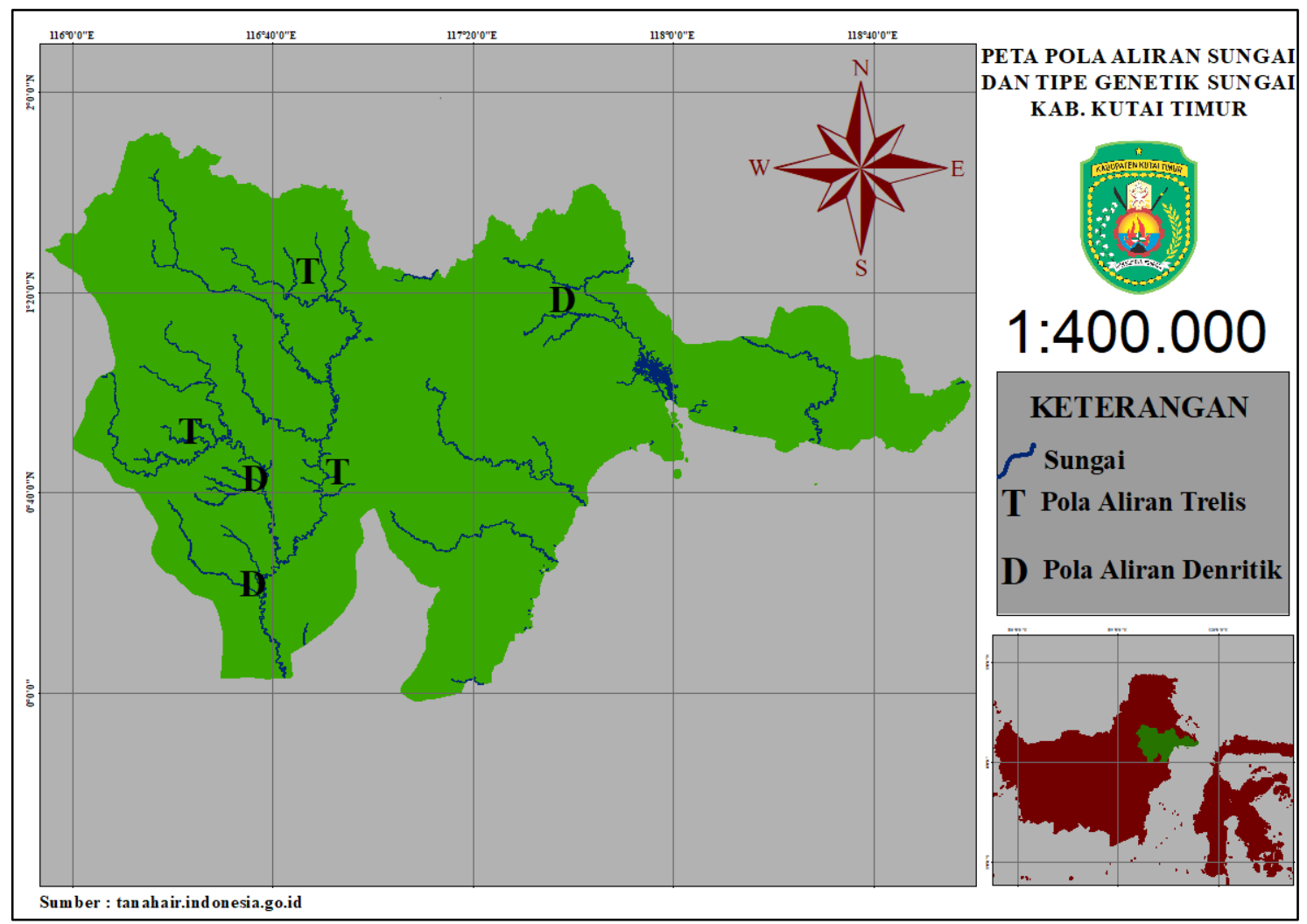

Gambar 3. Peta pola aliran sungai dan tipe genetik sungai di Kabupaten Kutai Timur.

Selanjutnya hasil perhitungan parameter morfotektonik sinusitas setiap aliran sungai yang terdapat di Kabupaten Kutai Timur didapatkan sebagai berikut:

Tabel 2. Hasil perhitungan parameter morfometri

\begin{tabular}{clccc}
\hline No & \multicolumn{1}{c}{ Nama Sungai } & $\begin{array}{c}\text { Panjang } \\
\text { sungai }(\mathrm{Km})\end{array}$ & $\begin{array}{c}\text { Kelurusan } \\
\text { Sungai }(\mathrm{Km})\end{array}$ & Sinusitas \\
\hline 1 & Sungai Kadang Kepala & 280,5 & 40,07 & 7,00025 \\
2 & Sungai Sangatta & 276,5 & 64,67 & 4,275553 \\
3 & Sungai Kelinjau & 381,8 & 98,83 & 3,863199 \\
4 & Sungai Wahan & 352,7 & 63,76 & 5,531681 \\
5 & Sungai Telen & 681,2 & 150,02 & 4,540728 \\
6 & Sungai Karangan & 282,6 & 81,64 & 3,461538 \\
7 & Sungai Bengalon & 331,1 & 66,98 & 4,943267 \\
\hline
\end{tabular}


Pada penelitian ini terdapat tujuh sungai yang dianalisis morfotektonik sinusitas sungai Semua sungai memiliki sinusitas yang tinggi menunjukkan bahwa seluruh sungai di Kabupaten Kutai Timur adalah sungai berliku. Nilai sinusitas di wilayah ini juga menandakan geomorfologi DAS dipengaruhi tektonik aktif.

Keaktifan tektonik ini dapat dihubungkan dengan keberadaan struktur geologi di daerah ini. Salah satunya adalah Sesar Mangkalihat. Sesar Mangkalihat yang berupa sesar mendatar, diidentifikasi di pantai timur Pulau Kalimantan dengan panjang 111 km (Pusat Studi Gempa Nasional, 2017).

\section{Kesimpulan}

Pola pengaliran dendritic dan trellis dijumpai pada daerah ini. Daerah Tenggara dan Timur Laut memiliki kemiringan lereng yang landai yang ditunjukkan oleh sungai berpola dendritic. Di arah Barat Laut terdapat sejumlah lipatan yang ditandai oleh sungai berpola trellis. Nilai sinusitas sungai yang didapatkan semua aliran sungai memiliki nilai di atas 1,5 yang artinya daerah Kabupaten Kutai Timur memiliki aktivitas tektonik yang yang aktif. Hal ini juga didukung oleh data struktur geologi yang menunjukkan bahwa di daerah Kalimantan Timur khususnya Kabupaten Kutai Timur terdapat sesar aktif yaitu Sesar Mangkalihat. Hasil dari penelitian ini diharapkan mampu membantu pengelolaan DAS di Kabupaten Kutai Timur, Provinsi Kalimantan Timur secara khusus dan daerah lainnya pada umumnya.

\section{Ucapan Terima Kasih}

Ucapan terima kasih saya ucapkan kepada Badan Geospasial Indonesia (BIG) yang telah menyediakan data penelitian. Dan tak lupa pula kepada Departemen Geofisika, Fakultas Matematika dan Ilmu Pengetahuan Alam, Universitas Hasanuddin yang telah mendukung penelitian ini.

\section{Referensi}

Augustio, O. and Setiawan, B. (2019) 'Pengaruh Kondisi Geologi Terhadap Perubahan Morfometri Sungai Musi Daerah Empat Lawang dan Sekitarnya', in Seminar Nasional AVoER XI. Palembang, 23-24 Oktober 2019: Fakultas Teknik Universitas Sriwijaya, pp. 523-527.

Hayani, S. and Sutriyono, E. (2020) 'Pengaruh Aktivitas Tektonik Terhadap Rekonstruksi Jalan di Desa Pekan Gedang dan Sekitarnya, Kecamatan Batang Asai, Kabupaten Sarolangun, Jambi’, Jurnal Geomine, 8(2), pp. 96-103. doi: https://doi/.org/10.33536/jg.v8i2.588.

Massinai, M. A. (2015) Geomorfologi Tektonik. Yogyakarta: Pustaka Ilmu.

Mejia, A. I. and Niemann, J. D. (2008) 'Identification and Characterization of Dendritic, Parallel, Pinnate, Rectangular, and Trellis Networks based on Deviations from Planform SelfSimilarity', Journal of Geophysical Research, 113(F02015), pp. 1-21. doi: 10.1029/2007JF000781.

Pusat Studi Gempa Nasional (2017) Peta Sumber dan Bahaya Gempa Indonesia Tahun 2017. First. Edited by M. Irsyam et al. Kab. Bandung: Kementerian Pekerjaan Umum dan Perumahan Rakyat Republik Indonesia.

Sukiyah, E. et al. (2012) 'The Drainage Basin Morphotectonic Role in The Development of Potency for Micro Hydro Electric Power in Southern Garut - Cianjur', Bionatura-Jurnal Ilmu-Ilmu Hayati dan Fisik, 14(1), pp. 1-11.

Timár, G. (2003) 'Controls on Channel Sinuosity Changes: a Case Study of the Tisza River, the Great Hungarian Plain', Quaternary Science Reviews, 22, pp. 2199-2207. doi: 10.1016/S02773791(03)00145-8.

Vienastra, S. (2018) 'Geomorfologi dan Morfometri Daerah Aliran Sungai (DAS) Tinalah di Kabupaten Kulonprogo Daerah Istimewa Yogyakarta', Jurnal Teknologi Technoscientia, 11(1), pp. 21-28. doi: 10.34151/technoscientia.v11i1.111.

Wahyudi, D. R. et al. (2015) 'Morphotectonic Control Towards Land Movement in Malalak Region, West Sumatra', Jurnal Lingkungan dan Bencana Geologi, 6(3), pp. 229-240. 
Xiao, C. et al. (2020) 'Model Test of the Effect of River Sinuosity on Nitrogen Purification Efficiency', Water, 12(1677), pp. 1-12. doi: http://dx.doi.org/10.3390/w12061677.

Zulkifli, L. et al. (2019) 'Keaktifan Tektonik Berdasarkan Kelurusan Punggungan, Kelurusan Sungai, dan Sinusitas Muka Gunung Daerah Leles, Jawa Barat', Padjadjaran Geoscience Journal., 3(3), pp. 168-174. 